\title{
LEARNING OBJECTIVE OF THE ANATOMY CIRCULATION SYSTEM FOR THE MEDICAL STUDENTS: A DELPHI STUDY
}

\author{
Marwatunnisa Al Mubarokah', Siti Munawaroh'², Yunia Hastami², Nanang Wiyono \\ ${ }^{1}$ Program Studi Kedokteran, Fakultas Kedokteran, Universitas Sebelas Maret, Surakarta - INDONESIA \\ ${ }^{2}$ Departemen Anatomi, Fakultas Kedokteran, Universitas Sebelas Maret, Surakarta - INDONESIA
}

Submitted: 15 August 2019; Final Revision from Author: 22 May 2020; Accepted: 23 June 2020

\begin{abstract}
Background: Anatomy is basic science that is important for preclinical students, clinics, and specialists. The development of medical science led to a reduced allocation of learning time in Anatomy. The imbalance between the amount of learning material with time allocation makes various effective teaching methods carried out and examined. The learning objectives guide the faculty in selecting teaching methods as well as appropriate evaluation to measure the progress of student understanding. This study aims to obtain detailed anatomical learning objectives regarding the circulation system for medical students as part of the development of the medical curriculum in Indonesia.
\end{abstract}

Method: This research is qualitative research with the modified Delphi method. The research subjects were anatomy lecturers in Indonesia who. The first round of the Delphi questionnaire was filled out by selecting the Bloom cognition domain between C1-C6 and the respondent composing the sentence of learning objectives according to the core material. The second round of respondents was asked to choose an important level from each point of learning objectives on the Likert Scale 1-4. The consensus level chosen is that $60 \%$ of the panel chooses on level 3 or 4 . The results of the second round are then processed to ensure the most appropriate selection of operational verbs and cognitive domains.

Results: The first Delphi round resulted in 74 learning objectives from 110 core material points with the cognitive domain between C1-C3. While the second round, Delphi generates 59 learning objectives. The third round which was not part of the Delphi method, these results were then consulted to anatomists of the circulatory system and came up with the 32 learning objectives.

Conclusion: The learning objectives of the circulation system that need to be known are 32 learning objectives, with cognitive domains varying between $\mathrm{C} 1-\mathrm{C} 3$, include cor, pericardium, mediastinum, arteries, veins, lymphatics system, prenatal and postnatal circulation, dan hepatic portal system.

Keywords: anatomy of circulatory system, Delphi method, anatomy learning objectives, lecturer consensus

\section{ABSTRAK}

Latar belakang: Ilmu Anatomi adalah ilmu dasar yang penting untuk dipelajari dan dipahami baik bagi mahasiswa preklinik, klinik, maupun dokter spesialis. Perkembangan ilmu kedokteran menyebabkan alokasi waktu pembelajaran ilmu Anatomi berkurang. Ketidakseimbangan antara banyaknya materi pembelajaran dengan alokasi waktu membuat berbagai cara pengajaran yang efektif dilakukan dan diteliti. Tujuan pembelajaran memandu dosen dalam memilih cara pengajaran serta evaluasi yang tepat untuk mengukur kemajuan pemahaman mahasiswa. Penelitian ini bertujuan untuk menyeragamkan tujuan pembelajaran anatomi sistem sirkulasi untuk mahasiswa kedokteran.

*corresponding author, contact: munafkuns@gmail.com 
Metode: Penelitian ini merupakan penelitian kualitatif dengan menggunakan metode Delphi termodifikasi. Subjek penelitian yaitu dosen anatomi di Indonesia yang dipilih dengan teknik purposive samping. Kuesioner Delphi putaran pertama diisi dengan memilih domain kognisi Bloom antara C1-C6 dan responden menyusun kalimat tujuan pembelajaran sesuai materi inti. Materi inti amatomi sistem sirkulasi merupakan hasil penelitian sebelumnya. Pada Delphi putaran kedua responden diminta memilih tingkat penting dari setiap poin tujuan pembelajaran pada kolom Likert Scale 1-4. Level konsensus yang dipilih yaitu 60\% panel memilih pada level 3 atau 4. Hasil dari putaran kedua kemudian dikonsultasikan kepada expert untuk memastikan pemilihan kata kerja operasional dan domain kognisi yang paling sesuai.

Hasil: Putaran pertama Delphi menghasilkan 74 tujuan pembelajaran dari 110 poin materi inti dengan domain kognitif antara C1-C3. Sedangkan Delphi putaran kedua menghasilkan 59 tujuan pembelajaran. Pada putaran ketiga yang tidak termasuk dalam metode Delphi, hasil putaran kedua tersebut kemudian dikonsultasikan kepada ahli anatomi sistem sirkulasi untuk mengakomodir masukan dari panel sehingga didapatkan 32 tujuan pembelajaran.

Kesimpulan: Tujuan pembelajaran sistem sirkulasi yang perlu diketahui terdapat 32 tujuan pembelajaran, dengan level kognitif $\mathrm{C} 1-\mathrm{C} 3$, meliputi cor, pericardium, mediastinum, pembuluh darah arteri, pembuluh darah vena, sistem lymphatica, sirkulasi pascanatal, sirkulasi prenatal, dan sistem portal hepatis.

Kata kunci: anatomi sistem sirkulasi, metode Delphi, tujuan pembelajaran materi anatomi, konsensus dosen anatomi.

\section{PRACTICE POINTS}

- Penelitian mengenai tujuan pembelajaran anatomi sistem sirkulasi ini melibatkan perwakilan dosen anatomi se-Indonesia

- Hasil penelitian diharapkan bisa memperjelas dan menyeragamkan pembelajaran untuk mencapai kompetensi anatomi minimal mahasiswa kedokteran Indonesia.

- Hasil penelitian memberikan manfaat sebagai masukan untuk pembelajaran anatomi sistem sirkulasi di Indonesia.

\section{PENDAHULUAN}

Anatomi adalah salah satu materi kedokteran tertua yang menjelaskan mengenai morfologi dan struktur tubuh manusia. ${ }^{1}$ Pada praktik kedokteran, anatomi berperan dalam pemeriksaan fisik yang mengarahkan kepada diagnosis, komunikasi kepada pasien dan keluarganya serta tenaga kesehatan lainnya, memandu prosedur intervensi invasif maupun pertolongan gawat darurat serta menentukan komplikasi. ${ }^{1.3}$ Oleh karena itu, anatomi menjadi salah satu ilmu dasar yang penting baik bagi mahasiswa preklinik maupun mahasiswa klinis, bahkan bagi dokter-dokter spesialis. ${ }^{2,4}$
Saat ini ilmu kedokteran begitu berkembang terutama mengenai ultrastruktur dan biomolekuler, namun durasi waktu pembelajaran mahasiswa justru semakin sedikit. ${ }^{5}$ Kompensasinya yaitu dengan mengurangi waktu kegiatan pembelajaran ilmu dasar, seperti anatomi, fisiologi, dan embriologi karena dialokasikan untuk pembelajaran materi kedokteran lainnya. ${ }^{6} \mathrm{Hal}$ ini secara tidak langsung mengakibatkan adanya peningkatan klaim terkait kesalahan anatomi pada praktik dokter di lapangan dibanding tahun-tahun sebelumnya. ${ }^{3}$

Alokasi waktu yang berkurang juga disebabkan karena adanya perubahan kurikulum menjadi 
Problem Based Learning, integrasi antara klinis dengan ilmu dasar. ${ }^{6,7}$ Banyaknya perubahan pada kurikulum kedokteran mendorong diselenggarakannya berbagai metode pengajaran agar pembelajaran Anatomi bisa benar-benar efektif tanpa menurunkan kualifikasi keamanan dokter saat menangani pasien., ${ }^{89}$ Sejauh ini metode pengajaran yang dilakukan antara lain dengan menggunakan diseksi cadaver, preparat plastinasi, demonstrasi menggunakan model, pemutaran video atau DVD, buku/atlas bergambar, software 3-dimensi komputer, dan metode radiologi serta Computer Assisted Learning (CAL) like anatomage table, virtual reality etc. ${ }^{9,10}$

Jam pembelajaran yang sedikit sedangkan materi Anatomi yang banyak memicu dilakukannya beberapa penelitian mengenai materi inti anatomi yang penting bagi mahasiswa. Seperti penelitian terdahulu mengenai penyusunan materi inti untuk seluruh regio tubuh, 8,11 identifikasi materi anatomi tulang yang sesuai dengan kasus klinis untuk mahasiswa kedokteran ${ }^{12}$, serta penelitian mengenai tujuan pembelajaran anatomi sistem respirasi untuk mahasiswa kedokteran. ${ }^{13}$

Tujuan pembelajaran didefinisikan sebagai perilaku hasil belajar yang diharapkan terjadi, dimiliki, atau dikuasai peserta didik sesuai kompetensi setelah mengikuti pembelajaran tertentu ${ }^{14}$ Tujuan pembelajaran berfungsi untuk memandu dosen dalam memilih kegiatan yang sesuai untuk mencapainya, memutuskan cara evaluasi yang efektif dalam menilai kemajuan pengetahuan siswa, serta berfungsi dalam memberikan gambaran mengenai proses pembelajaran dan menyajikan koherensi pengaruh pendidikan sesuai waktu. ${ }^{15}$ Tujuan dan aktivitas kegiatan pembelajaran bisa diukur dengan menggunakan taksonomi Bloom yang bisa dipahami setiap orang baik dalam skala nasional, regional, maupun internasional. ${ }^{16}$

Pada tahun 2017, telah dilakukan penelitian mengenai materi inti anatomi sistem sirkulasi oleh Munawaroh. ${ }^{17}$ Penelitian tersebut menghasilkan pokok-pokok materi anatomi yang perlu dipelajari. Karena masih berupa poin-poin materi inti, peneliti bermaksud untuk melanjutkan penelitian tersebut agar menghasilkan tujuan pembelajaran anatomi sistem sirkulasi yang disesuaikan dengan kompetensi dokter umum menurut Standar Kompetensi Dokter Indonesia (SKDI) dan korelasi klinis yang sering dijumpai oleh dokter umum.

\section{METODE}

Penelitian ini merupakan penelitian kualitiatif dengan menggunakan metode Delphi termodifikasi. Pemilihan sampel dengan menggunakan teknik purposive sampling dengan kriteria inklusi dosen yang pernah mengajar materi anatomi program studi kedokteran minimal 3 tahun serta memiliki latar belakang pendidikan dokter umum.

Metode Delphi diselenggarakan sebanyak dua putaran dan ditambah dengan satu putaran tambahan. Putaran pertama melibatkan 6 orang panel. Panel diberikan daftar materi inti anatomi yang dihasilkan oleh penelitian Munawaroh (2018). ${ }^{17}$ Alasan peneliti memilih daftar tersebut karena merupakan hasil konsensus dokter umum mengenai materi inti anatomi sistem sirkulasi sehingga diharapkan poinpoin materi inti tersebut merupakan materi yang sering ditemui dalam praktik klinis.

Kuesioner delphi putaran pertama terdiri dari 110 poin materi inti yang terbagi dalam beberapa topik, yaitu cor, pericardium, mediastinum, arteri, vena, sistema lymphatica, sirkulasi darah manusia (postnatal), sirkulasi darah fetus (pranatal), dan sirkulasi portal hepatis. Pada tahap ini panel memilih domain kognisi antara C1-C6 dari taksonomi Bloom dan menuliskan kalimat tujuan pembelajaran dengan kata kerja operasional yang sesuai untuk materi inti tersebut. Hasilnya akan dikompilasi untuk menyusun kuesioner Delphi putaran kedua.

Delphi putaran kedua melibatkan 20 orang panel. Panel diminta untuk menuliskan tingkat penting dari setiap poin tujuan pembelajaran pada kolom 1-4 Likert Scale. Tujuan pembelajaran inti didapatkan apabila 60\% panel memilihnya pada level 3 atau 4 .

Putaran ketiga tidak termasuk dalam rangkaian metode Delphi. Hasil kuesioner putaran kedua dikonsultasikan kepada beberapa ahli anatomi sistem sirkulasi yang telah mengajar dalam rentang 5-11 tahun. Putaran ini bertujuan untuk mengakomodir masukan dan saran dari panel pada putaran kedua, 
baik terkait susunan kalimat tujuan pembelajaran maupun domain kognitifnya.

\section{HASIL DAN PEMBAHASAN}

Subjek penelitan adalah 20 dosen anatomi dengan karakteristik responden dapat dilihat pada Tabel 1. Putaran pertama terdapat 6 responden dengan kuesioner disebarkan dalam bentuk naskah cetak. Sedangkan Delphi putaran kedua melibatkan 20 responden, dimana 6 responden merupakan panel dari putaran pertama dan 14 sisanya adalah responden baru. Pada putaran kedua, kuesioner sebagian diberikan dalam bentuk naskah cetak, dan sebagian melalui email.

Tabel 1. Karakteristik Subjek Penelitian

\begin{tabular}{lrc}
\multicolumn{1}{c}{ Karakteristik } & $\begin{array}{c}\text { Jumlah } \\
(\mathbf{N})\end{array}$ & $\begin{array}{c}\text { Persentase } \\
(\%)\end{array}$ \\
\hline Jeniskelamin & & \\
$\quad$ Laki-Laki & 10 & 50 \\
$\quad$ Perempuan & 10 & 50 \\
Usia (tahun) & & \\
30-34 & 10 & 50 \\
35-39 & 2 & 10 \\
40-44 & 3 & 15 \\
>44 & 5 & 25 \\
Pendidikan terakhir & & \\
S1 & 1 & 5 \\
S2 & 15 & 75 \\
S3 & 4 & 20 \\
Tahun kelulusan & & \\
1990-1995 & 1 & 5 \\
1996-2000 & 4 & 20 \\
2001-2005 & 4 & 20 \\
2006-2010 & 11 & 55 \\
>2010 & 0 & 0 \\
Lama mengajar dosen & & \\
anatomi (tahun) & & \\
3-5 & 4 & 20 \\
6-8 & 5 & 25 \\
9-11 & 4 & 20 \\
>11 & 7 & 55 \\
\hline
\end{tabular}

Responden kuesioner Delphi putaran kedua berasal dari 15 universitas yang tersebar di seluruh Indonesia. Domisili responden tersebar pada 13 kota yang berbeda di seluruh Indonesia, yaitu berada di
Pulau Jawa, Kalimantan, Sumatera, Nusa Tenggara, dan Sulawesi.

Kuesioner Delphi putaran pertama menghasilkan 74 tujuan pembelajaran yang kemudian tersaring menjadi sebanyak 59 setelah putaran kedua. Sedangkan putaran ketiga menghasilkan 32 tujuan pembelajaran anatomi sistem sirkulasi. Tujuan pembelajaran yang berkurang yaitu pada topik cor, mediastinum, dan arteri, sedangkan keenam topik lainnya tidak mengalami pengurangan. Topik arteri mengalami pengurangan paling banyak, yaitu menjadi 17 dari sebelumnya 27 poin tujuan pembelajaran.

Tujuan pembelajaran yang telah didapatkan tersebut kemudian dikonsultasikan lagi kepada ahli dan mengalami pengurangan menjadi 32 dari 59 tujuan pembelajaran. Pengurangan ini dikarenakan ada tujuan pembelajaran yang digabungkan dengan poin lainnya supaya lebih ringkas, serta beberapa tujuan pembelajaran lain dihilangkan sebab sudah termasuk dalam poin tujuan pembelajaran lainnya. Topik yang mengalami reduksi tujuan pembelajaran yaitu cor berkurang 5 poin, mediastinum 2 poin,arteri 11 poin, vena 3 poin, dan systema lymphatica 6 poin.

Penelitian ini bertujuan untuk mendapatkan tujuan pembelajaran anatomi sistem sirkulasi untuk mahasiswa kedokteran. Penelitian ini dilakukan dengan menggunakan metode Delphi agar dosen bisa mengetahui materi anatomi serta tingkat pemahaman yang harus dikuasai oleh mahasiswa dan sering ditemukan dalam praktik klinis. Metode Delphi dipilih karena metode ini dalam ranah kesehatan sering digunakan untuk menetukan prioritas. ${ }^{18}$ Jumlah putaran dalam penelitian adalah sebanyak dua putaran sebab apabila terlalu banyak putaran responden cenderung untuk keluar dari penelitian serta dikhawatirkan jawaban mereka tidak seoptimal yang seharusnya. ${ }^{19}$

Subjek dalam penelitian ini adalah dosen anatomi yang mengajar di berbagai institusi berbeda seIndonesia. Dosen anatomi dengan latar belakang pendidikan dokter umum dipilih karena mereka selain mengetahui materi anatomi yang sering ditemui dalam praktik, juga mengerti tingkat pemahaman yang harus dimiliki mahasiswa terhadap materi-materi tersebut. Pemilihan tersebut juga 
karena dosen berperan penting dalam membantu mahasiswa memvisualisasikan struktur anatomi tubuh, memahami teori-teori dan pengetahuan dasar anatomi, serta memandu dalam diskusi dan mendorong pemikiran-pemikiran yang konstruktif. ${ }^{20}$

Kriteria inklusi dalam penelitian ini yaitu dosen anatomi yang telah mengajar minimal tiga tahun. Kriteria ini sama seperti penelitian sebelumnya oleh Munawaroh (2016) ${ }^{11}$, dan tidak jauh berbeda dari penelitian oleh Smith $(2016)^{8}$ yang mensyaratkan minimal telah mengajar selama 5 tahun. Hal ini ditujukan agar dosen telah mengetahui tentang permasalahan kurikulum anatomi saat ini serta cara menyusun tujuan pembelajaran yang efektif dan efisien. Latar belakang pendidikan dokter umum menjadi penting agar materi anatomi serta tingkat pemahaman atau domain kognitifnya sesuai dengan kebutuhan dan kompetensi dokter kelak di masa depan. Institusi tempat bekerja yang berbeda-beda diharapkan bisa merepresentasikan dosen anatomi dari setiap wilayah di Indonesia sehingga hasil penelitian bisa menjadi acuan tujuan pembelajaran tingkat nasional.

Karakteristik panel dalam penelitian ini berbeda-beda, baik dari sisi jenis kelamin, usia, pendidikan terakhir, lama mengajar materi anatomi, tahun kelulusan profesi dokter, institusi tempat mengajar, serta daerah domisili. Perbedaan karakterisik tersebut tidak menjadikan jawaban responden mengenai tingkat pentingnya tujuan pembelajaran menjadi berbeda secara bermakna. Misalnya panel dari Pontianak, Kalimantan Barat dan Kupang, Nusa Tenggara Timur sama-sama menganggap bahwa pemahaman serta aplikasi dari fungsi dan proyeksi jantung sangat penting bagi mahasiswa kedokteran. Pendidikan terakhir panel juga beragam, ada lulusan S1, S2, maupun S3. Keberagaman ini tidak menjadikan hasil kuesioner antar panel berbeda secara bermakna. Contohnya responden lulusan S1 dan S3 samasama menganggap bahwa mengidentifikasi dan menunjukkan lokasi Arcus Aorta dan cabangcabangnya sangat penting bagi mahasiswa.

Domain kognitif dalam tujuan pembelajaran membantu pengajar atau dosen untuk menentukan puncak pengetahuan yang harus diberikan. Pembelajaran mendalam (deep learning) dibutuhkan untuk membuat kurikulum yang koheren, sedangkan pembelajaran superfisial (superficial learning) juga diperlukan agar pembelajaran yang membangun dan mendalam bisa tercipta. ${ }^{8}$

Hasil kuesioner putaran pertama menunjukkan bahwa tidak ada tujuan pembelajaran yang dikelompokkan dalam domain kognitif antara C4-C6. Hal ini dikarenakan domain kognisi menganalisis (C4), menilai (C5), dan menciptakan (C6) kurang sesuai dengan materi anatomi yang harus dipahami oleh calon dokter umum. Materimateri anatomi sistem sirkulasi mayoritas hanya membutuhkan mahasiswa paham hingga tingkat aplikasi (C3) terutama dalam kasus klinis. Menurut Smith (2016) tuntutan aplikasi klinis dan praktik yang aman oleh dokter adalah alasan perlu adanya konsensus mengenai tujuan pembelajaran materi anatomi. $^{8}$

Beberapa tujuan pembelajaran topik Cor yang masuk dalam domain kognitif C3 adalah materimateri yang berhubungan dengan pemeriksaan fisik kompetensi dokter umum serta penyakit-penyakit dengan tingkat kompetensi 4, 3A ataupun 3B dalam SKDI 2012. Misalnya tujuan pembelajaran mengenai fungsi jantung penting karena dengan mengetahui fungsi jantung normal, mahasiswa bisa mengetahui bagaimana mekanisme terjadinya gagal jantung sehingga membantu mereka dalam mendiagnosis dan memberikan tatalaksana awal serta merujuk pasien gagal jantung yang sesuai dengan kompetensi dokter umum yaitu $3 \mathrm{~A}$ dan 3 B. ${ }^{23,24}$

Tujuan pembelajaran yang berhubungan dengan pemeriksaan fisik yaitu mengenai proyeksi jantung, Arteri serta Vena Pulmonalis dan Arteri Coronaria, serta mengenai sistema kondusen cordis. Proyeksi jantung membantu dalam melakukan pemeriksaan inspeksi dada dan perkusi batas-batas jantung, sedangkan pada gambaran radiologis batas-batas jantung interpretasinya salah satunya ditentukan oleh posisi Arteri dan Truncus Pulmonalis. ${ }^{25}$ Sistema kondusen kordis penting dalam menjelaskan proses kontraksi otot-otot jantung dan sistem ini bisa dievaluasi dengan menggunakan alat elektrokardiogram (EKG) yang memberi informasi adekuat mengenai fungsi dan struktur jantung sehingga membantu penegakan diagnosis berbagai 
penyakit jantung. ${ }^{23}$ Pemeriksaan fisik inspeksi dada, perkusi batas jantung, EKG serta interpretasinya termasuk tingkat keterampilan 4A dimana dokter umum harus bisa melakukannya secara mandiri dan kemampuan ini harus dicapai saat lulus dokter. ${ }^{24}$

Domain kognitif memahami (C2) menuntut mahasiswa untuk merangkum, menginterpretasi, mengelompokkan dan membandingkan materi. Poin tujuan pembelajaran topik cor yang dikelompokkan dalam domain kognitif ini kebanyakan karena kasus klinis yang berkaitan termasuk dalam tingkat kompetensi 2, dimana dokter umum hanya diminta untuk mendiagnosis dan memberi rujukan yang tepat. ${ }^{24}$ Materi morfologi ruang jantung, apex dan basis cordis, innervasi jantung dengan Nervus Vagus, dan septum interatriale, interventrikulare serta fossa ovalis dikategorikan dalam domain kognitif C2. Pemahaman mengenai morfologi dan pembagian ruang jantung, baik ventrikel maupun atrium akan membantu dokter mengetahui apabila ada kelainan seperti kardiomiopati, baik yang dilatasi maupun restriksi. ${ }^{23}$ Katup jantung, baik valva tricuspidalis, mitral, trunci pulmonalis, dan aorta penting untuk diketahui peranannya terutama dalam merepresentasikan suara jantung yang bisa didengar melalui pemeriksaan auskultasi. ${ }^{23,25}$ Struktur di dalam jantung lainnya yaitu septum interatriale, septum interventrikulare, dan fossa ovalis penting karena apabila perkembangan embriologinya yang tidak sempurna bisa menyebabkan adanya Penyakit Jantung Kongenital (PJK) pada bayi baru lahir. ${ }^{25}$ Tujuan pembelajaran mengenai morfologi dan pembagian ruang jantung serta valva cordis dan septum interatriale, interventrikulare, dimasukkan dalam domain kognitif C2 agar menjadikan mahasiswa mampu membandingkan antara kondisi normal dan kondisi patologis sehingga bisa membantu dalam diagnosis pasien, seperti mitral stenosis dan mitral regurgitation, kardiomiopati,Ventricular Septal Defect (VSD) yang termasuk tingkat kemampuan 2 sehingga dokter umum hanya diminta untuk mendiagnosis dan memberikan rujukan yang sesuai. ${ }^{24}$

Topik pericardium didapatkan 2 tujuan pembelajaran dari hasil kuesioner Delphi kedua yang dimasukkan dalam domain kognitif memahami (C2). Cavum pericardii, liquor pericardii, serta pericardium berhubungan dengan aspek klinis pericarditis dan efusi pericardium. Cavum pericardii yang terisi cairan berlebih akan terakumulasi dalam saccus pericardii sehingga bisa menekan cor dan mengganggu fungsinya sehingga mengakibatkan gagal jantung. Pericardium juga salah satu komponen penyusun dinding jantung, dan bisa terinfeksi virus sehingga mengalami pericarditis. ${ }^{25}$ Pemahaman mengenai pericardium akan membantu dalam diagnosis pericarditis yang termasuk dalam tingkat kompetensi 2 bagi dokter umum. ${ }^{24}$

Poin tujuan pembelajaran yang didapatkan pada modifikasi putaran kedua Delphi topik Mediastinum yaitu 2 tujuan pembelajaran. Lokasi mediastinum superior dan inferior serta organ-organ yang terdapat didalamnya penting untuk membantu mendiagnosis tumor mediastinum dan komplikasi yang mungkin muncul. Mediastinum merupakan ruang yang ditempati organ-organ penting dimana sering mengalami lesi yang bermanifestasi klinis sebagai penyakit sistemik. Lesi pada mediastinum bisa berupa tumor maupun metastase tumor dimana apabila tindakan operatif diberikan bisa menimbulkan berbagai komplikasi tergantung organ yang terpengaruhi, seperti aritmia, syok kardiogenik, dan kerusakan Vena. ${ }^{26}$ Nervus Phrenicus memiliki serabut afferen yang menghantarkan nyeri ke dermatom C3-C5 apabila organ yang diinervasinya mengalami gangguan. ${ }^{25}$ Tujuan pembelajaran mengenai lokasi mediastinum superior dan inferior serta organ-organ di dalamnya dan topik mengenai Nervus Phrenicus dikategorikan domain kognitif mengaplikasikan (C3) karena mahasiswa bisa mengimplementasikannya dalam berbagai hal tergantung kebutuhan, salah satunya yaitu dalam bentuk penanganan syok kardiogenik yang merupakan kompetensi 3B dimana dokter umum harus bisa memberikan tatalaksana awal, mendiagnosis, dan merujuk..$^{24}$

Topik arteri didapatkan 6 tujuan pembelajaranm dimana 2 tujuan pembelajaran dikategorikan dalam domain kognitif C3 dan sisanya dimasukkan domain kognitif $\mathrm{C} 2$. Tujuan pembelajaran mengenai A.Radialis, A.Femoralis, A.Poplitea, dan A.Dorsalis Pedistermasuk dalam domain mengaplikasikan (C3) karena struktur-struktur tersebut penting dalam keterampilan pemeriksaan palpasi denyut 
nadi ekstremitas yang termasuk dalam tingkat keterampilan 4A yang harus bisa dilakukan oleh dokter umum secara mandiri. ${ }^{24}$ Poin-poin tujuan pembelajaran lainnya dikategorikan dalam domain kognitif C2 karena mayoritas tidak bisa diimplementasikan dalam bentuk pemeriksaan fisik maupun bentuk evaluasi pasien lainnya. Salah satunya tujuan pembelajaran mengenai Aorta dan cabang-cabangnya, mahasiswa hanya dituntut sampai paham karena salah satu kondisi klinis yang terkait yaitu koarktasio aorta yang termasuk tingkat kompetensi 1, dokter umum mampu mengenali dan menjelaskan. ${ }^{24}$ Koarkasio aorta adalah kondisi dimana lumen aorta mengalami penyempitan di bagian distal pangkal Arteri Subclavia Sinistra sehingga suplai oksigen ke ekstremitas inferior dan abdomen berkurang. ${ }^{25}$

Tujuan pembelajaran topik vena dikelompokkan menjadi C3 dua poin tujuan pembelajaran, C2 satu poin, dan $\mathrm{C} 1$ sebanyak satu poin. Materi yang dikategorikan dalam domain kognitif C3 yaitu vena yang terlibat dalam pemeriksaan fisik maupun prosedur keterampilan lainnya. Salah satunya yaitu tujuan pembelajaran mengenai Vena Jugularis externa yang berperan dalam pemeriksaan Tekanan Vena Jugularis (JVP) yang termasuk dalam dokter umum harus bisa melakukannya tanpa pengawasan (Tingkat keterampilan 4). ${ }^{24}$

Materi tentang Vena Jugularis interna, Vena Subclavia, Vena Saphnea Magna et Parva, dan Vena Femoralis dikelompokkan dalam domain kognitif memahami (C2) sebab tidak perlu diaplikasikan dalam pemeriksaan fisik maupun penunjang yang termasuk tingkat kompetensi dokter umum. Vena Cava Superior termasuk vena sistemik besar yang sering dijadikan muara dari pungsi vena-vena kecil lainnya yang berfungsi untuk memasukkan obatobatan maupun cairan, seperti prosedur dialisis. ${ }^{25}$ Vena sistemik besar tidak banyak terlibat dalam berbagai kondisi klinis sehingga tujuan pembelajaran mengenai Vena Cava Superior et Inferior dikategorikan dalam domain kognitif mengingat (C1). Pada tingkat ini mahasiswa diminta untuk mengingat kembali materi yang telah dipelajarinya.

Limfonodus merupakan salah satu organ yang menjadi penentu prognosis karsinoma, karena metastase karsinoma ke limfonodus menandakan agresivitas dari suatu tumor ${ }^{27}$, Misalnya karsinoma pulmo yang menyebar melalui vasa lymphaticus menuju limfonodus di hilum pulmonis, mediastinum, dan pangkal leher. ${ }^{25}$ Limfadenitis adalah infeksi lokal pada limfonodus yang disebabkan karena proliferasi berlebih dari sel-sel di dalam limfonodus untuk melawan antigen. Pembesaran limfonodus ini bisa diketahui dengan pemeriksaan fisik yaitu palpasi kelenjar limfe. ${ }^{28}$ Limfadenitis dan palpasi kelenjar limfe termasuk dalam tingkat keterampilan 4A dimana dokter umum harus bisa memberikan tatalaksana dan melakukan pemeriksaan tanpa pengawasan. ${ }^{24}$

Sirkulasi darah manusia dibedakan menjadi dua, yaitu sirkulasi darah sistemik dan sirkulasi paru. Sirkulasi darah sistemik yaitu yang menyulai darah ke seluruh tubuh kecuali paru sehingga disebut juga sirkulasi perifer. ${ }^{29}$ Sirkulasi darah fetus berbeda dengan sirkulasi darah manusia berbeda karena lingkungan hidup fetus dan manusia berbeda. Sirkulasi darah fetus memiliki bangunan-bangunan berbeda dari jantung manusia, seperti ductus arteriosus, ductus venosus dan formaen ovale ${ }^{23}$ Struktur-struktur dan sistem sirkulasi fetus akan mengalami penyesuaian setelah fetus lahir. Apabila penyesuaian struktur-sturktur tersebut tidak terjadi secara sempurna maka akan mengakibatkan adanya kelainan pada jantung yang disebut Penyakit Jantung Kongenital (PJK). ${ }^{23}$ Tujuan pembelajaran mengenai struktur-struktur yang berkaitan dengan sistem sirkulasi baik saat masih fetus maupun saat sudah mengalami penyesuaian ketika lahir dikategorikan dalam domain kognitif memahami (C2). Hal ini dikarenakan PJK seperti Patent Ductus Arteriosus (PDA) termasuk dalam kompetensi 2 yaitu dokter umum mampu mendiagnosis dan memberi rujukan yang tepat ${ }^{(24)}$.

Sistem Vena porta hepatis mengalirkan darah vena yang kandungan oksigennya sedikit namun kaya nutrisi dari organ abdomen ke liver. Aliran darah tersebut dibawa oleh Vena Porta Hepatis yang merupakan gabungan dari Vena Lienalis dan Vena Mesenterica Superior. ${ }^{25}$ Pada sistem ini terdapat anastomosis-anastomosis portiosistemik, yaitu di lapisan submukosa inferior esofagus, anus, dan 
dinding anterior abdomen di sekeliling umbilicus ${ }^{25,30}$ Jika terdapat peningkatan tekanan vena porta hepatis, maka bisa terjadi varises pada anastomosisanastomosis tersebut, salah satu manifestasinya yaitu hemorroid. ${ }^{25}$ Tujuan pembelajaran mengenai sistem vena porta hepatis dan anastomosisnya dikategorikan dalam domain kognitif C3 karena beberapa penyakit yang terkait dengannya, seperti Hemorrhoid merupakan kompetensi 4A sehingga dokter umum harus bisa memberikan tatalaksana yang sesuai. ${ }^{24}$

\section{KESIMPULAN}

Konsensus dosen anatomi mengenai tujuan pembelajaran sistem sirkulasi yang didapatkan dari hasil penelitian ini adalah sejumlah 32 tujuan pembelajaran dari 110 materi inti yang terdapat di kuesioner. Tujuan pembelajaran tersebut diantaranya: cor sebanyak 10 topik, pericardium 2 topik, mediastinum 2 topik, pembuluh darah arteri 6 topik, pembuluh darah vena 4 topik, sistem lymphatica 3 topik, sirkulasi pascanatal 2 topik, sirkulasi prenatal 1 topik, dan sistem portal hepatis 2 topik. Sedangkan menurut domain kognitifnya, didapatkan hasil tujuan pembelajaran dengan pengelompokan yaitu: mengingat (C1) 1 poin, memahami (C2) 15 poin, dan mengaplikasikan (C3) 16 poin.

\section{SARAN}

Penelitian ini masih terfokus pada materi anatomi sistem sirkulasi saja. Saran untuk penelitian selanjutnya bisa menambahkan untuk topik anatomi lainnya agar semua topik anatomi bisa didapatkan tujuan pembelajaran anatomi minimal untuk bekal mahasiswa kedokteran

\section{DEKLARASI KEPENTINGAN}

Para penulis mendeklarasikan bahwa tidak terdapat konflik kepentingan apapun terkait studi pada naskah ini.

\section{KONTRIBUSI PENULIS}

Marwatunnisa Al Mubarokah - menyusun tinjauan pustaka dan merangkum hasil penelitian serta menyusun naskah publikasi
Siti Munawaroh - menyusun metode Delphi dan meninjau ulang naskah publikasi

Yunia Hastami - menyusun rancangan penelitian dan hasil penelitian

Nanang Wiyono - meninjau ulang konten anatomi sistem sirkulasi dan mengkoordinasikan panel penelitian

\section{DAFTAR PUSTAKA}

1. Hirt B, Shiozawa T. Clinical anatomy as a modern concept for 21st century teaching, postgraduate education, and research. Kistato Medical Journal. 2013; 43: 99-103

2. Vorstenbosch MATM, Kooloos JGM, Bolhuis SM, Laan RFJM. An investigation of anatomical competence in junior medical doctors. Anatomical Sciences Education. 2016; 9: 8-17.

3. Turney BW. Anatomy in a modern medical curriculum. Ann R Coll Sur Engl. 2007; 89: 104-107.

4. Alhagh EA, Sarbishegi M, Barfroshan S, Abedi A. Medical students knowledge about clinical importance and effective teaching methods of anatomy. Shiraz E-Med J.2017; 18(12):e14316.

5. Bergman EM, Prince KJAH, Drukker J, Van der Vleuten CPM, Scherpbier AJJA. How much anatomy is enough?. Anatomical Sciences Education. 2008;1: 184-188.

6. Drake RL, McBride JM, Lachman N, Pawlina W. Medical education in the anatomical sciences :The winds of change continue to blow. Anatomical Sciences Education. 2009; 2: 253-259.

7. Satheesha NP. Teaching human anatomy in the medical curriculum: A trend review. International Journal of Advanced Research. 2017; 5 (4): 445-448.

8. Smith CF, et al. Anatomical Society core regional anatomy syllabus for undergraduate medicine: The Delphi process. Journal of Anatomy. 2016; 228 (1): $2-14$

9. Craig SJ, Tait N, Mcandrew DJ. Review of anatomy education in Australian and New Zealand medical schools. ANZ J Surg., 2010; 80: 212-216. 
10. Kerby J, Shukur ZN, Shalhoub J. The relationships between learning outcomes and methods of teaching anatomy as perceived by medical students. Clinical Anatomy. 2011; 24: 489-497

11. Munawaroh S, Rahayu GR, Suryadi E, Mada UG. Identification of Anatomy Contents for Medical Students Using Delphi Technique. 2017; 6(2):98-107.

12. Swamy M, Venkatachalam S, McLachlan J. A Delphi consensus study to identify current clinically most valuable orthopaedic anatomy components for teaching medical students. BMC Med Educ. 2014;14:230.

13. Musfidasari AA, Munawaroh S, Wiyono N, Hastami Y. Anatomy lecturer's consensus concerning the learning objectives of the respiratory system for medical students. Procedings of the $2^{\text {nd }}$ ICO-HELICS. 2019; $51-$ 59.

14. Utami TH. Indikator dan tujuan pembelajaran dalam rencana pelaksanaan pembelajaran. Prosiding seminar nasional MIPA. 2010; 1-4

15. Bonaci CG, Mustata RV, Ienciu A. Revisiting bloom's taxonomy of educational objectives. The Macrotheme Review A Multidisciplinary Journal of Global Macro Trends. 2013; 2(4): $144-160$.

16. Krathwohl DR. A revision of Bloom's taxonomy: An overview. Theory into Practice. 2002; 41(4).

17. Munawaroh S, Hanifa FM, Wiyono N, Hastami Y, Kartikasari MND, Hermasari BK. Delphi technique: consensus of anatomy circulatory system core syllabus for medical student. Jurnal Pendidikan Kedokteran Indonesia, 2018; 7(2): 107-117.

18. Sinha IP, Smyth RL, Williamson PR. Using the Delphi technique to determine which outcomes to measure in clinical trials: Recommendations for the future based on a systematic review of existing studies.PLoS Medicine, 2011; 8(1).
19. Boulkedid R, Abdoul H, Lustau M, Sibony $\mathrm{O}$, Alberti C. Using and reporting the delphi method for selecting healthcare quality indicators: A systematic review. PLoS ONE. 2011; 6(6).

20. Halima I. Anatomy "Peer Teaching" in Medical School: ALiterature review. MedEdPublish. 2016. https://doi.org/10.15694/mep.2016.000033

21. Trevelyan GE, Robinson, N. Delphi methodology in health research: how to do it?. Europan Journal of Integrative Medicine. 2015; 7: 423-428.

22. Shariff NJ. Utilizing the Delphi survey approach: A Review.Journal of Nursing Care. 2015; 4 (3): $1-6$.

23. Lilly LS. Pathophysiology of heart disease: a collaborative project of medical students and faculty. Baltimore, MD, Wolters Kluwer/ Lippincott Williams \& Wilkins. 2016

24. KKI. Standar Kompetensi Dokter Indonesia (SKDI). 2nd ed. Indonesia: Konsil Kedokteran Indonesia. 2012

25. Drake RL, Vogl W \& Mitchell AWM. Gray's Anatomy for Student. Elsevier. 2014

26. Junior RS, Magliari MER, Lopez JMA. Mediastinal diseaseL clinical and therapeutic aspects. J.pneumolgia. 2003; 29(4). Doi:10.1590/ s0102-35862003000400007

27. Cho JK, Hyun SH, Choi N, Kim MJ, Padera TP, Choi JY\& Jeong HS. Significance of lymph node metastasis in cancer dissemination of head and neck cancer. Translational oncology, 2015; $8(2), 119-25$.

28. Cross C. Lymphadenitis. Comperhensive Pediatric Hospital medicine. 2007; 201-204

29. Guyton AC, Hall JE. Buku Ajar Fisiologi Kedokteran. Edisi 11. Penterjemah: Irawati, Ramadani D, Indriyani F. Jakarta: Penerbit Buku Kedokteran EGC. 2006

30. Moore KL, Dalley AF. Clinically oriented anatomy. Philadelphia, Lippincott Williams \& Wilkins. 1999 